\title{
Evaluation of mixture swirl in the cylinder chamber in a conceptual system with combustion surrounded by inactive gases
}

\begin{abstract}
Internal combustion engines have seen a reduction of the dynamics of their efficiency growth in recent years. All kinds of new modifications and changes introduced in this field can only manage changes of engine efficiency at the level of a fraction of a percent. Considering the concept of unification of SI and CI internal combustion engine structures, one can expect to see their efficiency increase by the reduction of losses, whose causes and occurrence is commonly known. The improvement of the combustion system is mainly related to the reduction of thermal losses generated in this process. Therefore, the current issue is the advanced analysis of any possibilities of improving the combustion conditions and more fully understanding the processes that accompany them. The authors of the article see such a possibility in the conceptual control of the combustion process, which aims to obtain a combustible mixture surrounded by nonflammable gases. This way the flame contact with the cylinder walls is limited, which should in turn contribute to reducing the heat exchange with the walls. This research is a continuation of previous research work; current work focuses on determining the actual distribution of gases in the combustion chamber using the advanced shadow photography method. The article specifies the effect of nonflammable gas injection pressure increase on the area of the boundary layer formed between the non-flammable gases and cylinder walls.
\end{abstract}

Key words: rapid compression machine, schlieren photography, advance combustion management, particle image velocimetry

\section{Introduction}

The current stage of internal combustion engines development is characterized by a considerable structural similarity of spark-ignition and compression-ignition engines. This unification concerns not only similar boost systems, but also the combustion systems. Both systems use direct fuel injection into the combustion chamber. Similarities also occur in exhaust aftertreatment systems, as sparkignition engines also now work with values of excess air coefficient greater than 1 (stratified charge). A similar analogy can be expected in exhaust gas recirculation (EGR) systems. The EGR system that is already widely used in compression-ignition engines is also starting to play an increasingly important role in spark-ignition engines.

The main reason for using an exhaust gas recirculation system in internal combustion engines is the ability to reduce the emission of nitrogen oxides $\left(\mathrm{NO}_{\mathrm{x}}\right)$ by reducing the maximum combustion temperature. Increasing the proportion of recirculated gases for high engine loads can effectively reduce the occurrence engine knock (in the SI engine) and reduce the temperature of the exhaust gases. The negative aspect of using this system is - as the amount of gasses transferred through the EGR increases the fill factor decreases, which leads to the reduction of engine torque. Research carried out by Alger [2] indicates that a high proportion of recirculated exhaust gases reduces the flame propagation rate and leads to combustion process instability. The use of new injection systems in DI SI engines [3] and further testing of these systems in CI engines [4], contribute to the increase of specific power values obtained from these systems. Hence, the combination of advanced injection systems with EGR systems can increase the efficiency of these systems.

Internal combustion engines continue playing an important role as a source of propulsion for motor vehicles. Although there is a growing trend in the automotive industry of the development of vehicles with hybrid drive systems or plug-in vehicles, the modernization of conven- tional internal combustion engines is essential for maximizing the efficiency of vehicles using them. In the era of strong legal restrictions regarding fuel consumption and engine exhaust emissions from vehicles, one of the development directions of these drives is using alternative propulsion systems (hybrid and hydrogen drives) [16, 21, 25]. Classic drives using spark-ignition and compressionignition internal combustion engines are subjected to modifications that can be summarized as actions tuning the drive systems for operation with direct fuel injection and boost systems [5, 9, 11, 14].

For a dozen or so years, a trend in the construction of car engines could be seen, consisting of obtaining increased values of engine operating indicators with reduced stroke volumes and a reduced number of cylinders [15, 17]. The actions taken by producers fall mainly into two categories:

- downsizing primarily based on reducing the engine displacement while using additional systems to increase the average useful pressure of the engine to compensate, - downspeeding - a procedure involving engine speed reduction with the simultaneous use of additional systems increasing the average useful pressure.

In addition, downsizing was divided into two types: static and dynamic [5, 24]. Static downsizing is meant to reduce the engine overall size by limiting its displacement volume (usually achieved through the reduction of the number of cylinders) while compensating for its other operating parameters so that they do not change. Dynamic downsizing is the reduction of the engine's displacement achieved by temporarily disconnecting some of the cylinders depending on the engine operating conditions. This type of downsizing has so far been applied very rarely and used mainly for multi-cylinder engines.

The combination of these two approaches of internal combustion engines modification by manufacturers is called rightsizing. It means the proper selection of the drive unit (its power) for a given vehicle. This is particularly important in cases where a combustion engine with reduced 
capacity was used in a vehicle where it operated in the conditions of reduced overall efficiency.

In order for all the engine construction changes mentioned so far to make a real contribution towards reducing the impact on the global environment, it is necessary for advanced combustion engines to be introduced in all vehicle models. The development packages for engine series manufactured by Mazda, presented by Hirose and Hitomi [14], adopt the so-called common architecture concept. The first generation of Skyactive engines (with a displacement of $1.3-2.5 \mathrm{dm}^{3}$ ) was introduced based on this concept. In order to increase efficiency, it is necessary to reduce the losses of thermal energy supplied with the fuel (heat loss through exhaust, cooling, pumping and mechanical). In that study [14], the authors point out that just seven control factors may enable the reduction of these losses. Figure 1 shows Mazda's strategy in the pursuit of creating the ideal internal combustion engine, for both spark ignition and compression ignition engines.

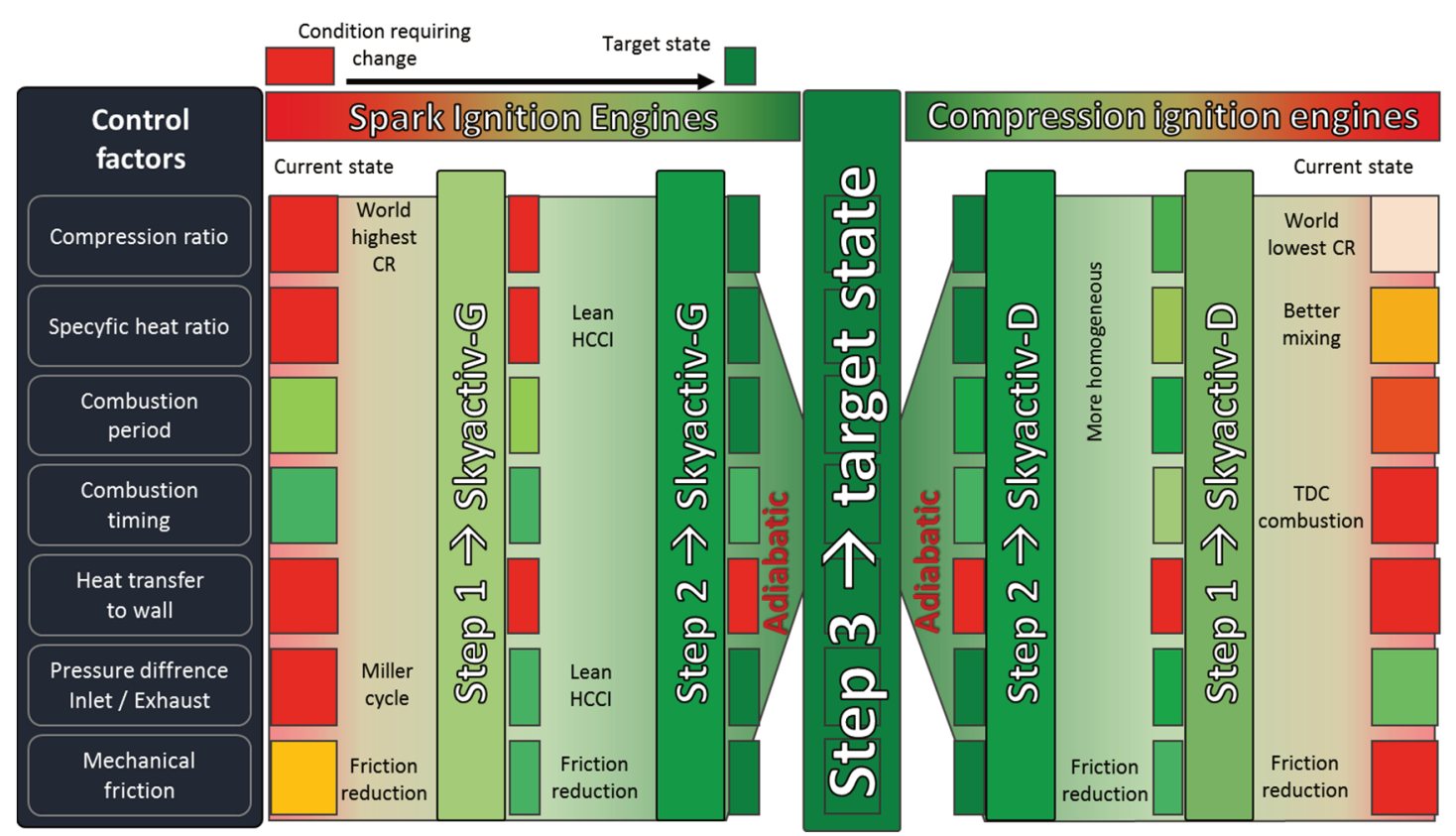

Fig. 1. The concept of complete modernization of internal combustion engines; CI and SI engines striving for common construction [14]

According to the presented concept, in order to obtain the target state (marked in green in Fig. 1), the combustion process should be made adiabatic. This means that it is necessary to control the heat exchange with the cylinder walls during combustion. Considering the concept of SI and CI internal combustion engine construction unification, one can expect their efficiency to increase due to reducing some of the losses present in current constructions. Hence, the improvement of the combustion system mainly means the reduction of thermal losses generated in this process. Therefore, the current research issue is an advanced analysis of the possibilities of improving fuel combustion conditions and fully describing the accompanying processes. Among the many possibilities of increasing the efficiency of the engine, the article will focus on the aspect of the possibility of the engine thermal efficiency increase with a new combustion system using recirculated exhaust gases.

\section{Aim of research}

Combustion in an internal combustion engine is a highly dynamic process, and the phenomena occurring during the pre-flame processes take place as a result of chain reactions [1]. Once initiated the process cannot be stopped. To properly initiate the combustion process, the fuel-air mixture must be prepared accordingly. The quality of the combustion process achieved can be assessed only after its completion, often analyzing several combustion cycles (which results from the necessity of averaging the values obtained, due to the non-repeatable nature of this process).

One of the main elements used to supply gases to the combustion chamber is the air intake system. The ability to generate the appropriate turbulence of injected gases depends on its construction. The concept of its operation involves creating a rotational movement of gases in the cylinder. The whirling motion is caused using a twist (angular momentum) created as the mixture flows into to the combustion chamber. In order to obtain more circular flow of gases, the air intake channels must be properly shaped. However, as the swirling motion increases, the flow resistance also increases, which leads to the deterioration of the fill factor $\eta_{\mathrm{v}}$.

In air intake systems of internal combustion engines, the gases are given a swirled motion through a specific geometry of inlet channels. The methods of inducing a vortex motion can include using:

- a tangential channel (generates a bend relative to the cylinder axis),

- a spiral channel (generates a bend relative to the valve axis),

- a different position (lift) of the valve seat relative to the head combined with the head gathering the material in the valve seat proximity,

- turbulence generator in the channel (Fig. 2), 
- variable lift of valves,

- deactivation of valves.

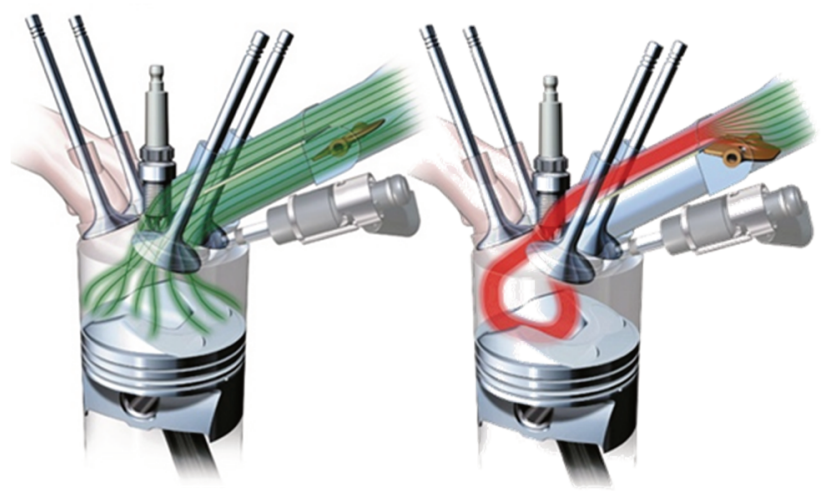

Fig. 2. The use of a turbulence generator in the form of a shutter in the inlet channel forcing a tumble motion of the gases (for example used in Audi 2.0 FSI engines) [15]

In most internal combustion engine designs the previously listed types of turbulence occur simultaneously. It is possible for one of them to dominate depending on the shape of the intake channel, the shape of the piston crown, head surface and the engine speed. A given type of turbulence can be noticeable in both macro- and microscale in specific phases of the engine's operation cycle.

There is not much information in the literature regarding research into the combustion process control using the turbulent swirl of recirculated fumes. Analyzes regarding the possibility of generating turbulence are directed primarily at CI engines [7]. There is not much research on the combustible mixture formation in SI engines with direct gasoline injection taking into account the nature of the mixture formation involving recirculated exhaust gases. In direct injection, creating too much turbulence can result in the fuel being taken along with the gases, which leads to problems with mixture ignition at the spark plug. The uniformity of the exhaust gas supplied to each cylinder is currently also a problem.

The studies performed by Perini [7] concerning the modeling of the compression ignition engine cylinder turbulence indicate the possibility of creating a controlled turbulence in the chamber using special dampers which can be controlled to generate a radial swirl as shown in Fig. 3.

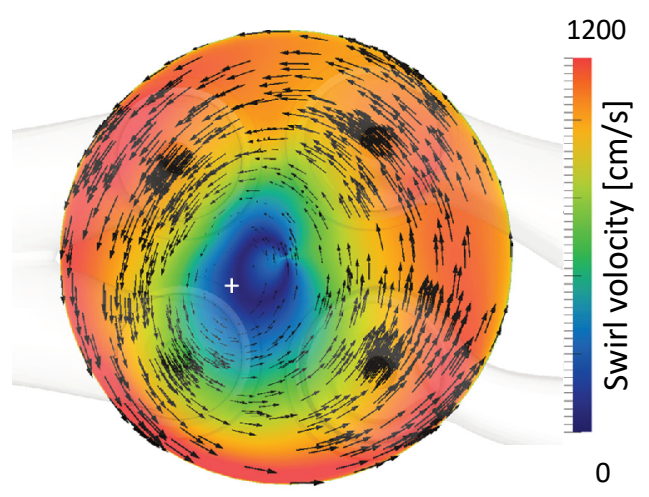

Fig. 3. Predicted tangent velocity field in the measurement plane; the "+" sign means the calculated vortex center (colors correspond to the velocity of the mixture turbulence) [23]
The analysis of the SI engines gas distribution is therefore not an investigated aspect that requires further experimental research, such as the research presented in this article.

An experimental analysis of the aspect used to determine the possibility of generating swirling motion of gases in the cylinder chamber of a rapid compression machine has been attempted in this paper. In order to do this, the rapid compression machine cylinder head was adapted to allow non-flammable gases to be introduced near the cylinder walls. Injection of gases took place as shown in Fig. 4.

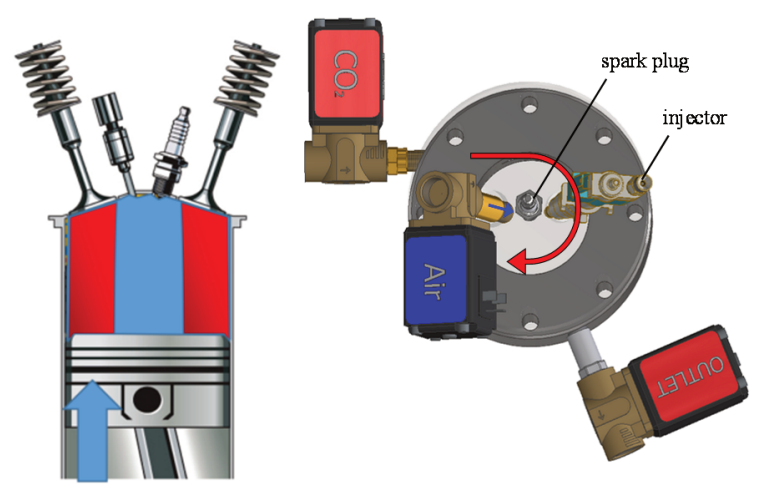

Fig. 4. The concept of radial layering of non-flammable (red) and flammable (blue) gases with the visualization of the injection method (using electromagnetic valves) to the RCM chamber

\section{Research object}

Experimental research on gas turbulence in the combustion chamber have some limitations as a result of the test method used. It is impossible to accurately determine the distribution of inactive and active gases in the working volume of the cylinder. There are research methods that enable partial recognition of the stratification of the gas charge depending on their composition (shadow method schlieren); it is possible to perform tests using speckle pattern (marking part of the mixture). Regardless of the method chosen to determine the air-fuel dose distribution in the chamber, whenever the image is recorded using a camera, it is only possible to produce images of a flat twodimensional exposure.

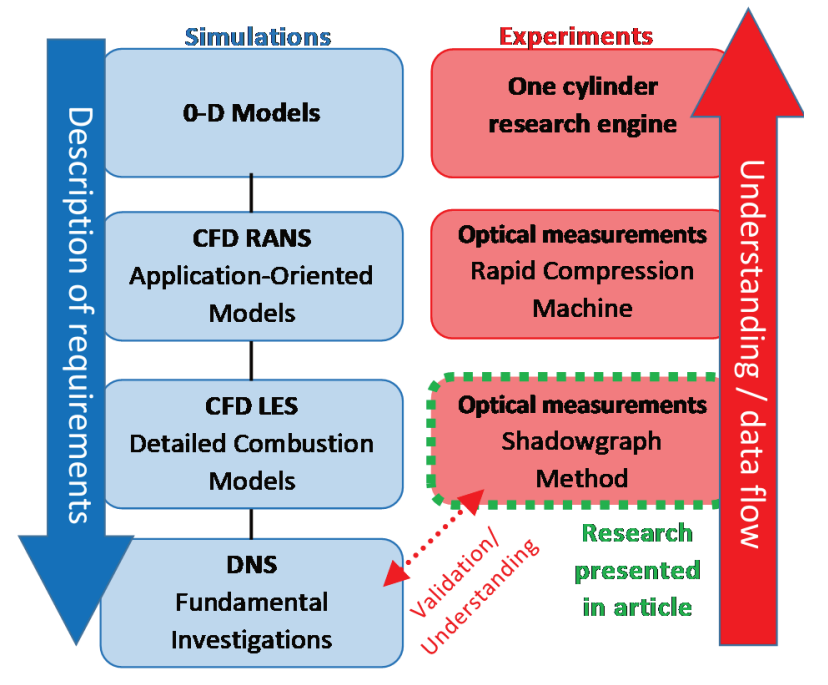

Fig. 5. Hierarchical research approach to the research topic using the simulation research method and the experiment [6] 
Model tests enable the extension of the experimental analysis of gas swirls in the combustion chamber with information on: the mass fraction distribution of the components supplied to the combustion chamber and the threedimensional current characteristic. The hierarchical approach to solving research problems presented in [6] was used for author's research. The connection between simulation and experimental research is presented in Fig. 5.

The simulation and experimental investigations regarding the possibility of generating mixture turbulence in earlier publications $[8,12,18]$ were verified using the experimental method presented in this article.

The rapid compression machine was adapted for optical testing in shadow photography (Fig. 6). The test bench was constructed based on the instructions and tips listed in [12, 13, 20, 22, 27]. The main elements of the system were: a concave mirror (1) with diameter $\phi=150 \mathrm{~mm}$ and focal $\mathrm{f}=750 \mathrm{~mm}$, mirror (9) semi-permeable 50:50 at wavelength $450-650 \mathrm{~nm} \pm 10 \%$ with a diameter $\phi=50 \mathrm{~mm}$ from Thorlabs, placed at a $45^{\circ}$ angle to the optical axis, a light source in the form of a diode (10) and a knife-edge (6). The remaining elements of the test bench are: electromagnetic valve supplying $\mathrm{CO}_{2}$ to the cylinder chamber (2), glass $\phi=$ $85 \mathrm{~mm}$ enabling optical access to the combustion chamber (3), gas outlet solenoid valve from the cylinder chamber (4), mirror with optical access from the piston crown side (5) and a camera (7) with a lens (8).

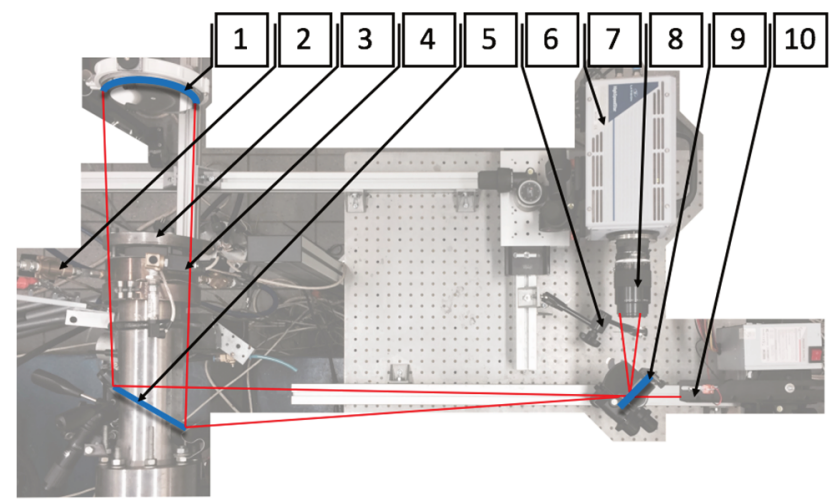

Fig. 6. The rapid compression machine test bench adapted for optical testing in shadow photography (description in the text)

Optical tests were performed using a high speed camera, the parameters and selected filming speeds along with the maximum resolution values are shown in Table 1.

Table 1. LaVision HighSpeedStar 5 camera parameters [18]

\begin{tabular}{|l|c|}
\hline Image sensor type & CMOS \\
\hline $\begin{array}{l}\text { Size of the } \\
\text { photocathode } \\
\text { pixel }\end{array}$ & $17 \mu \mathrm{m} \times 17 \mu \mathrm{m}$ \\
\hline $\begin{array}{l}\text { Maximum } \\
\text { resolution }\end{array}$ & $1024 \times 1024$ pixels \\
\hline $\begin{array}{l}\text { Selected } \\
\text { maximum image } \\
\text { capture speed }\end{array}$ & $\begin{array}{r}\text { 5000 photo/s at resolution } \mathbf{5 1 2} \times \mathbf{5 1 2} \text { (capture } \\
\text { speed used for the research) } \\
20000 \text { photo/s at resolution } 384 \times 152\end{array}$ \\
\hline $\begin{array}{l}\text { Gray-scale } \\
\text { recording }\end{array}$ & Monochromatic 10 -bit \\
\hline Optical range & 380 nm to $800 \mathrm{~nm}$ \\
\hline
\end{tabular}

The schlieren method (shadow method) was developed in the $17^{\text {th }}$ century by Robert Hooke. This technique was then refined by Toepler in the $19^{\text {th }}$ century $[20,22]$. A general schematic explaining shadow measurements is shown in Fig. 7.

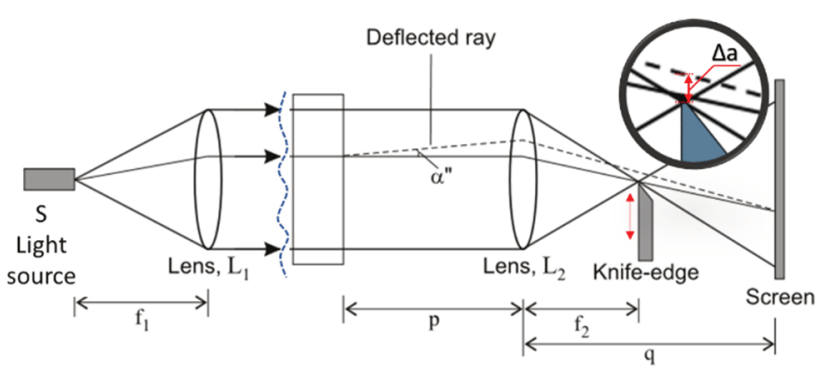

Fig. 7. Diagram of shadow visualization [21] (description in the text)

The light source is placed at the focus of the lens and produces a wide parallel beam passing through the sample. The light is focused by the lens (L2), and then reaches the screen of the measuring camera, set so as to obtain a sharp image of the measured sample. In the focus of the lens (L2) the knife-edge was set, also known as an optical knife, that is moved in a plane perpendicular to the optical axis of the system. The path of any ray of light that has not been affected by changes in sample density is marked with a solid line, and the angle at which the light refracted $\alpha$ (when such density changes occur) - was marked with a dashed line. The distance of the skewed light beam from the optical axis at the lens L2 focal point is equal to:

$$
\Delta \mathrm{a}=\mathrm{f}_{2} \alpha
$$

In order to obtain the appropriate sensitivity of the measurement system, it is necessary for the image of the light source that arrives at the focus of the L2 lens (with dimensions a0 x b0) was partially cut by the knife-edge. This value is strictly determined by the value of $a_{K}$ as shown in Fig. 8.

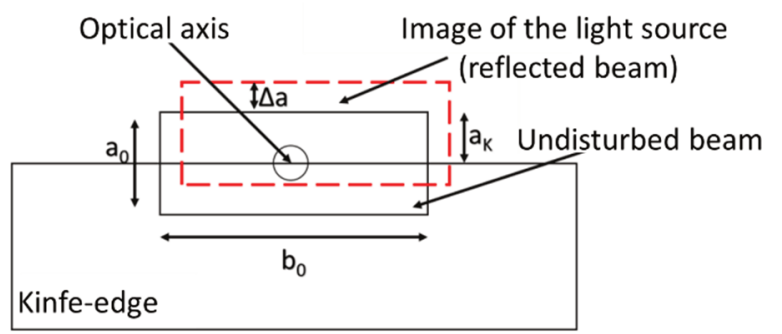

Fig. 8. Knife-edge principle of operation [22]

As a result, the rays that have been refracted from the axis, increase the camera's matrix illumination (if $\Delta \mathrm{a}$ is positive) or are blocked on the blade (if $\Delta \mathrm{a}$ is negative) causing local drop in the luminosity of the observed sample. The relationship regarding the contrast at a given point is defined as follows:

$$
\frac{\Delta \mathrm{I}}{\mathrm{I}_{\mathrm{k}}}=\frac{\mathrm{f}_{2}}{\mathrm{a}_{\mathrm{k}} \mathrm{n}_{\mathrm{a}}} \int_{\mathrm{L}} \frac{\partial \mathrm{n}}{\partial \mathrm{y}} \mathrm{dz}
$$


where: $I_{k}$ - the intensity of light on the screen, in the absence of changes in the sample density and the knife-edge cutting off the light source image by the value $a_{k}, \Delta I=I-I_{k}$ - the difference in light intensity at a given point of the screen relative to $I_{k}, n_{a}$ - the refractive index value outside the measurement space.

Thus, by measuring the intensity of light in various places of the camera matrix, a derivative of the refractive index can be determined at the corresponding points of the measuring space. This allows determining the derivative of density:

$$
\frac{\partial \rho}{\partial \mathrm{y}}=\frac{\rho}{\mathrm{n}-1} \frac{\partial \mathrm{n}}{\partial \mathrm{y}}=\frac{1}{\text { const }} \frac{\partial \mathrm{n}}{\partial \mathrm{y}}
$$

This method is widely used for internal combustion engines research. There are many variations in the configuration of light sources, lenses or mirrors. In the presented study the optical path of the test bench was designed as described in Fig. 9.

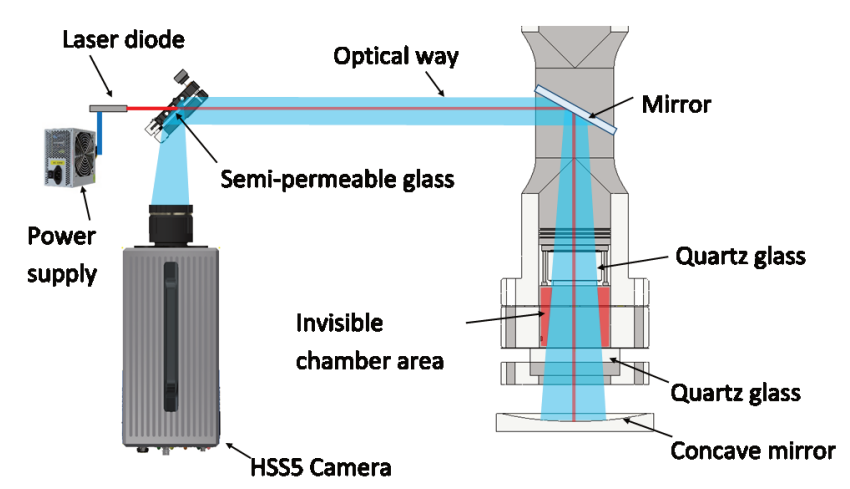

Fig. 9. Test bench construction schematic [6]

One of the main construction elements is the semipermeable mirror EBS2 from ThorLabs, which transmits a beam of light in the ratio 50:50, in the visible range 450 $600 \mathrm{~nm}$ (Fig. 10). This mirror allows directing light into the measurement space while simultaneously allowing to record the sample image on the side of the light source.

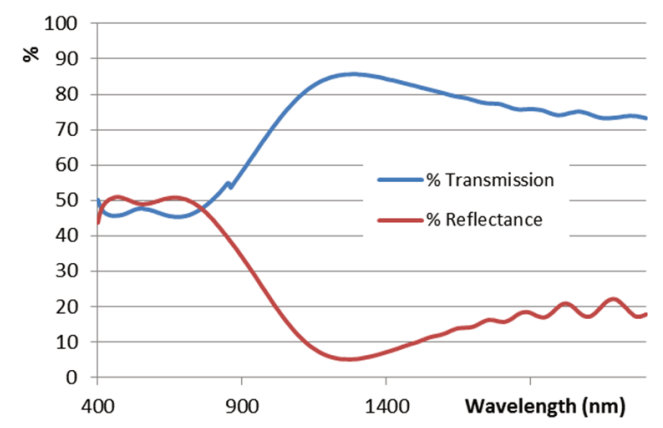

Fig. 10. Transmission and reflection properties of the EBS2 semi-permeable mirror [10]

The streak method allows registering the density differrence of two mediums. Hence, the choice of gases for the experiment was analyzed and presented below. The article analyzes the combustion in a spark-ignition engine system. In such systems, the stoichiometric mixture $(\lambda=1)$ under- goes combustion, and the process in theory follows the equilibrium equation:

$$
\mathrm{C}_{\mathrm{m}} \mathrm{H}_{\mathrm{n}}+\left(\mathrm{m}+\frac{\mathrm{n}}{4}\right) \mathrm{O}_{2} \rightarrow \mathrm{mCO}_{2}+\frac{\mathrm{n}}{2} \mathrm{H}_{2} \mathrm{O}
$$

$\mathrm{C}_{\mathrm{m}} \mathrm{H}_{\mathrm{n}}$ in the equation refers to the fuel, which for SI engines is gasoline, consisting mainly of aliphatic (chain) hydrocarbons with the number of carbon atoms in the chain ranging from 6 to 12. There are also some amounts of aromatic hydrocarbons and unsaturated hydrocarbons found in gasoline, but they are not a significant portion of its composition [28]. During gasoline combustion in the presence of air, exhaust components are produced, and the amount of harmful or toxic compounds created in this process depends directly on the combustion system quality. Typical values for exhaust gases concentration from fuel mixed with air in SI engines are shown in Fig. 11. The main gaseous toxic components of the exhaust are: carbon monoxide, unburnt hydrocarbons and nitrogen oxides.

Due to the sensitivity of the research method (shadow photography), the use of real exhaust gas in tests would cause interpretation problems of determining the boundary between these gases. The air contains about $78 \%$ nitrogen and about $21 \%$ oxygen, while in the exhaust gas, even though the oxygen content is fractional, the nitrogen content is still prevalent. In the gases emitted by the SI internal combustion engine, the share of carbon dioxide becomes noticeable, as it reaches over $12 \%$.
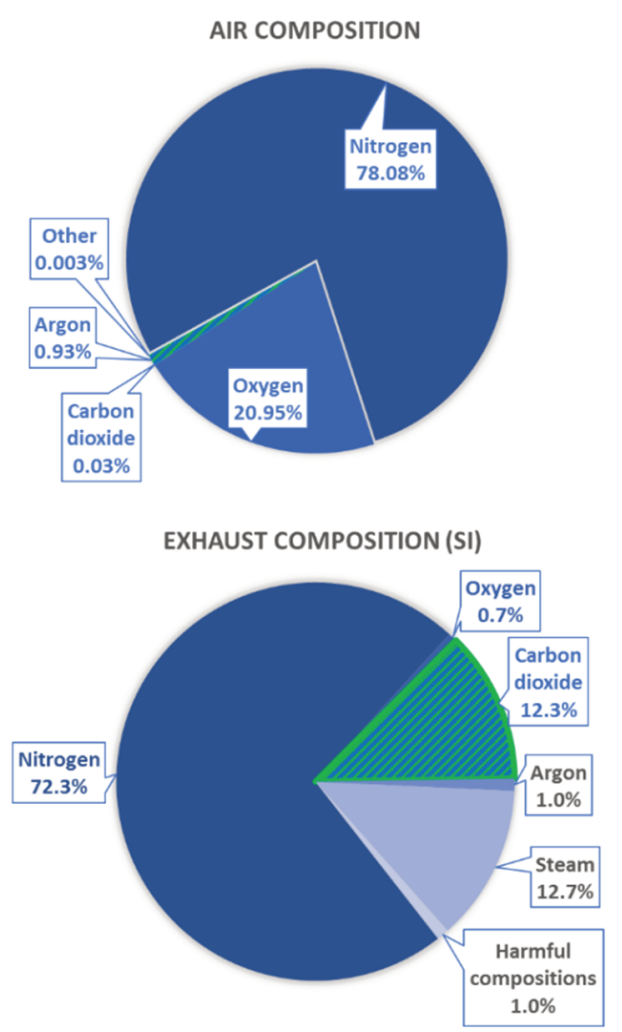

Fig. 11. The composition of air and exhaust gases in the SI engine (with a catalytic converter) [26]

The following postulates were considered to be criteria for the selection of gas to simulate recirculated exhaust gases in the research: 
- a non-flammable gas,

- greater density than air,

- a component in a SI engine exhaust gases,

- easy to store and supply to the RCM combustion chamber.

Two gases meet the above criteria: carbon dioxide and nitrogen. Because nitrogen is present in the air and in the exhaust gases, and its density differs only by $3 \%$ from the density of air, its use would result in the observed changes in density differences to be very small. Carbon dioxide, on the other hand, has density more than $50 \%$ greater than air. It is also non-flammable and present in exhaust gases, which is why it was chosen for the performed experiments.

\section{Optical analysis of gas distribution}

The processing method of the measuring material using LaVision DaVis software is presented in Fig. 12. The first stage of postprocessing consists of determining the registration cross-section and defining the further processing area (defining the mask). The circular marker visible in the images was used for determining the concave mirror center with respect to the optical path.

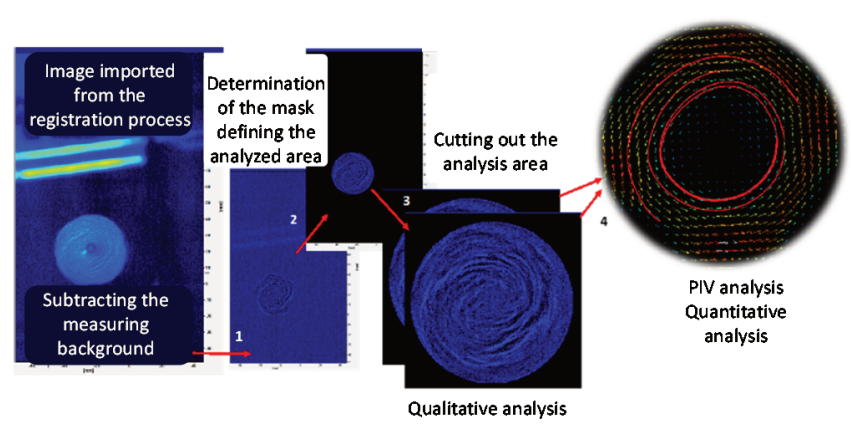

Fig. 12. Streak method test results processing

The streak method allowed observation of the gas swirl in the rapid compression machine chamber. Sequence shown in Fig. 13 is an example. Image analysis (of consecutive frames) allows a qualitative assessment of the flow of gas in the chamber (carbon dioxide and air). This movement clearly takes on the character of radial turbulence.

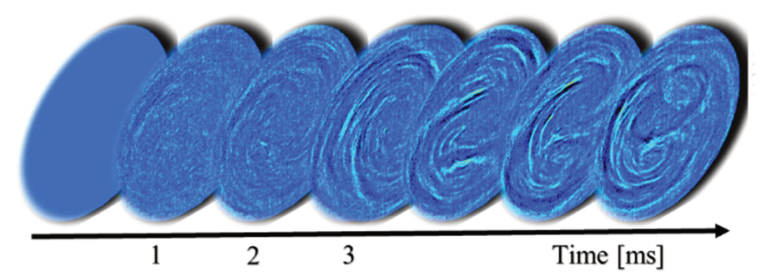

Fig. 13. An example of the images showing gas swirl in the chamber

The results of gas turbulence tests recorded for two different injection pressures were presented in Fig. 14. Injecting a non-combustible gas with a pressure of 10 bar causes greater gas turbulence than injection at 6 bar (this tendency was expected). In addition, there is a relationship between the non-combustible gases injection pressure and the width of the resulting gas layer. In the tests, a larger width of the swirled gas layer in the chamber was obtained at a pressure of 10 bar (different radii of air are marked in red).

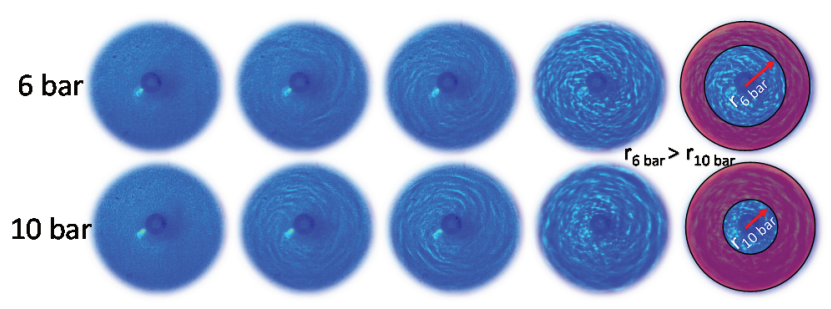

Fig. 14. $\mathrm{CO}_{2}$ gas swirl comparison for the pressures of 6 and 10 bar

In order to determine the scale range of the process, further processing of the results is necessary. To achieve this, analysis of the film material was performed using the PIV (Particle Image Velocimetry) method. The PIV anemometry method is used in velocity area measurements [27]. It is a non-invasive method (because it does not require the use of flow sensors that disturb the flow) and consists of comparing images representing the same background with a moving object. The time between recorded images is an important parameter in this method that allows determining the degree of change (in the performed research the image capture frequency was $5 \mathrm{kHz}$, so the time between images was $0.2 \mathrm{~ms}$ ). Usually, in order to carry out PIV measurements, it is necessary to use a laser to light up the flowing molecules (methods using speckle pattern). The so-called masks are chosen based on local displacements of markers from two images, (these markers are the only element that can introduce a disturbance in the tested system). For each mask position, a two-dimensional correlation function is calculated (Fig. 15). This is a statistic method and it requires that there is an appropriate number of markers within the mask.

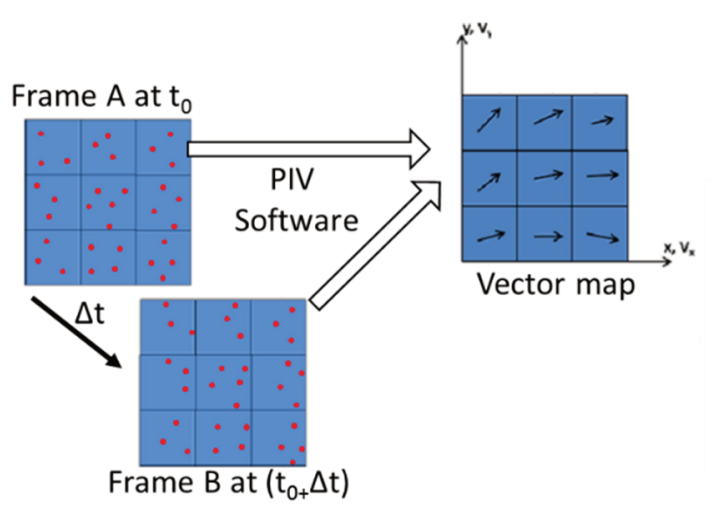

Fig. 15. The principle of using PIV in calculating the flow rate [19]

Although in tests of non-flammable gas turbulence in a rapid compression machine, no speckle pattern was used, an attempt was made to determine velocity vectors using the DaVis software and the PIV image analysis procedure implemented in it.

Images of gas swirls in the entire cylinder chamber were chosen for a cross-correlation. Masks were added to the images imported for the PIV calculations in order to determine the image area in which the changes taking place in the cylinder were located. The selection of appropriate velocity vector calculation parameters was another aspect. Multi-pass iterations for a fixed image size of $32 \times 32$ pixel, a $75 \%$ overlay of areas, and a minimum number of transi- 
tions set to 3 . After calculating the velocity vectors the results settings were changed to display the current lines, (red solid line in Fig. 16), which corresponds to the average turbulence in the cylinder volume. In addition, reference vectors on the chamber radius were selected and their parameters determined (Fig. 17).
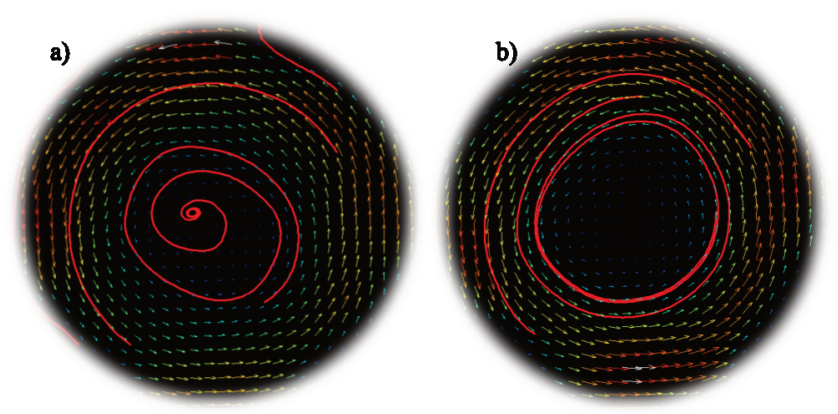

Fig. 16. Gas current lines with $\mathrm{CO}_{2}$ injection pressure of: a) 6 bar, b) 10 bar

The shape of the current line in the air flow analysis in the vicinity of the non-flammable gas indicates that at increased $\mathrm{CO}_{2}$ gas pressure (10 bar), the size of the space without turbulence (ring formed from the current line) is increased - Fig. 16. It is possible to introduce flammable mixture of air and fuel into this space, which should result in the combustible mixture being surrounded by nonflammable gases. In a situation where the $\mathrm{CO}_{2}$ injection pressure was 6 bar, radial turbulence could also be seen, but its velocity was lower. Additionally, the current lines were arranged in a screw shape, which indicates a lower uniformity of the created layer.

Each obtained vector was described by its direction and length equal to the speed. Since the measurement method does not have a typical speckle pattern, the speed analysis was done in relative values. The maximum speed that was calculated was taken as $100 \%$. Then for each vector (Fig. 17) its parameters were determined in order to show the relative velocity of the swirl (Fig. 18).

a)

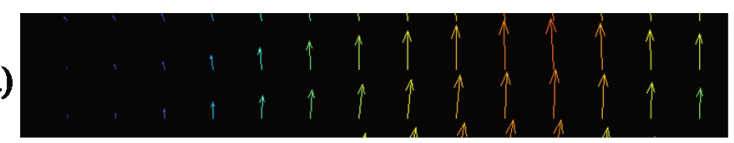

b)

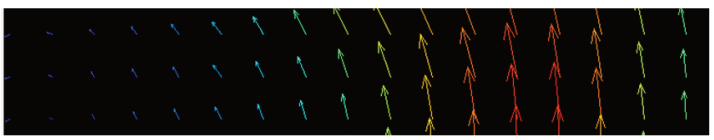

Fig. 17. Velocity vectors with $\mathrm{CO}_{2}$ injection pressure of: a) 6 bar, b) 10 bar

Note that the image capture area is smaller than the actual cylinder size. Hence it should not be assumed that at lower pressures, the boundary layer of the non-flammable gas is insufficient to achieve the assumed results. The flow velocity has increased by $30 \%$ in the area $15-22 \mathrm{~mm}$ from the center of the cylinder (the diameter of the visible image is equal to $50 \mathrm{~mm}$, the RCM cylinder is $80 \mathrm{~mm}$ in diameter). The decrease in velocity near the border of the recorded image probably results from the lack of information (points, markers) outside the observed area.

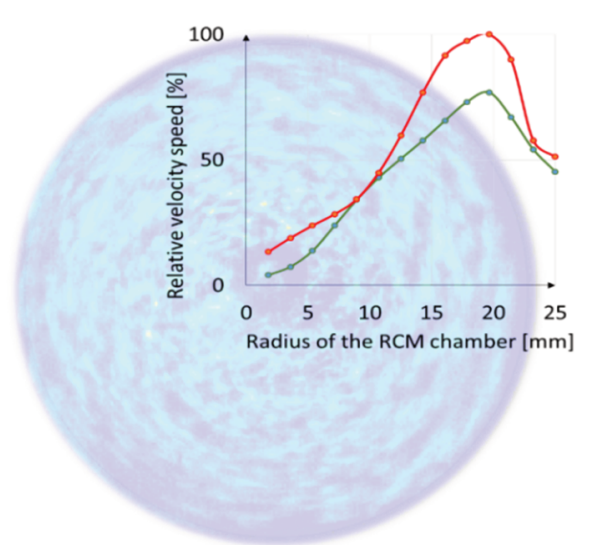

Fig. 18. Relative vortex velocity in a rapid compression machine chamber at $\mathrm{CO}_{2}$ injection pressure equal to: 6 bar (green), 10 bar (red)

The uniformity of the formed ring surrounding the center of the combustion chamber is evidenced by the lengths of velocity vectors described by the color palette (Fig. 19) on a scale from 0 to $100 \%$. The colors black and blue indicate the smallest values, and the colors orange and red - the greatest values of the obtained gas velocity.

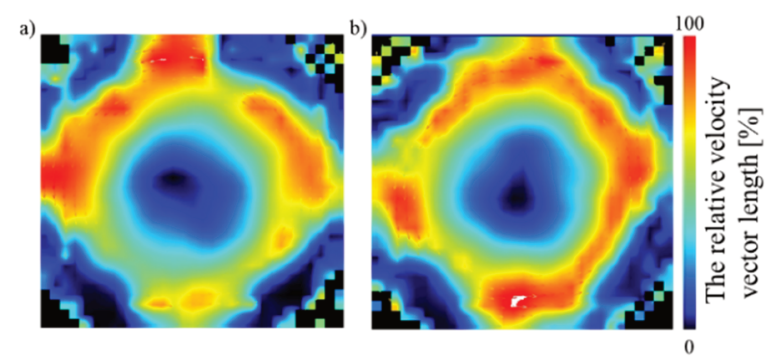

Fig. 19. Turbulence velocity at $\mathrm{CO}_{2}$ injection pressure equal to: a) 6 bar, b) $10 \mathrm{bar}$

\section{Conclusions}

Optical method of recording the turbulence using shadow method and using carbon dioxide as a non-flammable gas, showed strong response to the observed phenomena. The shadow method allows obtaining information necessary to confirm the assumptions made on the creation of a new combustion system. As a result, it was possible to analyze the combustion process in the vicinity of nonflammable gases, which will become a part of further research of the article authors.

It has been shown that a 60 -percent increase in the pressure of non-flammable gas injection causes about a $30 \%$ increase in the relative velocity of gases near the cylinder walls (20 $\mathrm{mm}$ from the combustion chamber center). However, as the injected gases pressure increased, no significant increase in gas velocity around the combustion chamber center was observed. Initiating the combustion process will be possible in this region, assuming that the injection and ignition of the combustible mixture takes place in a sprayguided system.

The research presented in this paper was performed within the statutory work, project no. 05/52/DSPB/0279. 


\section{Nomenclature}

$\mathrm{a}_{\mathrm{k}} \quad$ light beam corresponding to knife-edge

CFD computational fluid dynamics

CI compression ignition

CMOS complementary metal-oxide-semiconductor

$\mathrm{CO}_{2} \quad$ carbon dioxide

DI direct injection

EGR exhaust gas recirculation

$\mathrm{f}$ focal lengths of lens

HSS high speed star (camera model)

$\mathrm{I}_{\mathrm{k}} \quad$ illumination from knife-edge to the screen
LES large eddy simulation

$\mathrm{n}_{\mathrm{a}} \quad$ refractive index value outside the measurement space

$\mathrm{NO}_{\mathrm{x}} \quad$ nitrogen oxides

PIV particle image velocimetry

RANS Reynolds-averaged Navier-Stokes equations

RCM rapid compression machine

SI spark ignition

$\eta_{\mathrm{v}} \quad$ volumetric efficiency

\section{Bibliography}

[1] A hierarchy of models for simulating experimental results, https://www.research-collection.ethz.ch (accessed 10.11.2017).

[2] ALGER, T. Developments in high efficiency engine technologies and an introduction to SwRI's dedicated EGR concept. Directions in Engine-Efficiency and Emissions Research (DEER), Southwest Research Institute, San Antonio, 2012.

[3] ALGER, T. Gasoline engine technology for high efficiency. https://crcao.org/work-shops (accessed 09.04.2018).

[4] BLANK, H., DISMON, H., KOCHS, M. et al. EGR and air management for direct injection gasoline engines. SAE Technical Paper 2002-01-0707, 2002, DOI:10.4271/2002-010707.

[5] BOROWSKI, P., PIELECHA, I., CIEŚLIK, W. et al. Statyczny i dynamiczny downsizing silników spalinowych. Logistyka. 2013, 3, 671-679.

[6] CIEŚLIK, W., PIELECHA, I. Analysis of the possibilities to achieve adiabatization process of combustion surrounded by inactive gases in RCM. Combustion Engines. 2017, 168(1), 27-31. DOI:10.19206/CE-2017-104.

[7] CIEŚLIK, W., PIELECHA, I., KAPUSTA, Ł. The concept of combustion system with use of recirculated exhaust gas in the spark ignition engine. Combustion Engines. 2015, 162(3), 257-263.

[8] CIEŚLIK, W., PIELECHA, I., WISŁOCKI, K. Optical identification of the combustion of air-fuel mixture surrounded by non-combustible gas in a rapid compression machine. Archivum Combustionis. 2017, 37(2), 93-106.

[9] CRAWFORD, M. 3 Emerging Trends in Automotive Engineering, 2013.

[10] Economy beamsplitters, www.thorlabs.com (accessed 5.06.2016).

[11] FLAIG, B., BEYER, U., ANDRÉ, M. Exhaust gas recirculation in gasoline engines with direct injection. MTZ. 2010, 71, 22-27.

[12] GOPAL, V., KLOSOWIAK, J.L., JAEGER R. et al. Visualizing the invisible: the construction of three low-cost schlieren imaging systems for the undergraduate laboratory. European Journal of Physics. 2008, 29(3), 607-617.

[13] HARGATHER M., SETTLES G.S. Natural-backgroundoriented schlieren imaging. Experiments in Fluids. 2010, 48, 59-68.

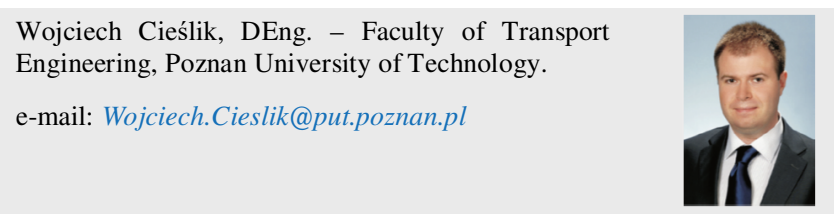

[14] HIROSE, I., HITOMI, M. Mazda's way to more efficient internal combustion engines. MTZ. 2016, 5(77).

[15] It's all about flow, http://www.ai-online.com (accessed 18.05.2017).

[16] KAWAMOTO, N., NAIKI, K., KAWAI, T. et al. Development of new 1.8-liter engine for hybrid vehicles. SAE Technical Paper 2009-01-1061, 2009.

[17] KOWALEWICZ, A. Podstawy procesów spalania. WNT, Warszawa 2000.

[18] LaVision GmbH, www.lavision.de (accessed 15.07.2016).

[19] Main components required for PIV setup, http://www.andor.com (accessed 16.04.2018).

[20] MERCER, C. Optical metrology for fluids, combustion and solids. Springer. 2003.

[21] MERKISZ, J., PIELECHA, J. Observations from PEMS testing of combustion engines of different applications. Combustion Engines. 2018, 174(3), 40-55. DOI: 10.19206/ CE-2018-305

[22] PANIGRAHI, P.K., MURALIDHAR, K. Schlieren and shadowgraph methods in heat and mass transfer. Springer. 2012.

[23] PERINI, F., MILEC, P.C., REITZ, R.D. A comprehensive modeling study of in-cylinder fluid flows in a high-swirl, light-duty optical diesel engine. Computers \& Fluids. 2013, 105, 113-124.

[24] PIELECHA, I., CIEŚLIK, W., BOROWSKI, P. et al. Reduction of the number of cylinders in internal combustion engines - contemporary trends in downsizing. Combustion Engines. 2014, 159(4), 12-25.

[25] PIELECHA, I., CIEŚLIK, W., SZAŁEK, A. Operation of electric hybrid drive systems in varied driving conditions. Eksploatacja i Niezawodnosc - Maintenance and Reliability. 2018, 20(1), 16-23. DOI. 10.17531/ein.2018.1.3.

[26] PIELECHA, J. (red.), Badania emisji zanieczyszczeń silników spalinowych. Wydawnictwo Politechniki Poznańskiej, Poznań 2017.

[27] SETTLES, G.S. Schlieren and shadowgraph techniques. Visualizing phenomena in Transparent Media. Springer. 2001.

[28] Skład benzyn i olejów napędowych, metody ich produkcji, http://www.vmc.org.pl (dostęp z dnia 27.03.2018).

Prof. Ireneusz Pielecha, DSc., DEng. - Faculty of Transport Engineering, Poznan University of Technology.

e-mail: Ireneusz.Pielecha@put.poznan.pl 